\title{
Immunobiochemical modulations caused by clomazone in Swiss albino mice
}

\author{
Mohamed Nassef
}

\begin{abstract}
Background: Recently, we reported immunological and hematological perturbations in Swiss albino mice exposed to clomazone (CMZ) (Nassef, The Egyptian Journal of Experimental Biology (Zoology) 13(1):91-101, 2017).

Aim: To continue searching immunological perturbations of $C M Z$, the main goal of the current study was to investigate the probable immunobiochemical perturbations caused by $C M Z$ and to evaluate the alleviating role of vitamin $C$.

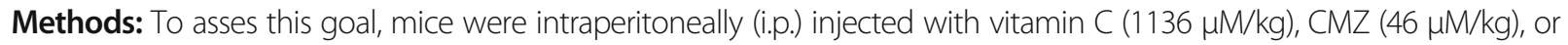
CMZ plus vitamin C with the same dose of each, daily for 4 weeks. Changes in relative weights of immune-related organs (spleen and thymus), renal functions (urea and creatinine), liver functions [alanine aminotransferase (ALT), aspartate aminotransferase (AST), alkaline phosphatase (ALP), lactate dehydrogenase (LDH) and total protein], and immunoglobulin (lg) isotype (lgA, $\operatorname{lgG}$, and $\operatorname{lgM}$ ) concentrations in addition to the proliferative capacity of CMZ-exposed murine lymphocytes were investigated.

Results: Results showed that CMZ injection caused a significant decrease in body weight gain along with significant decrease in the relative weights of the spleen and thymus. Values of ALT, AST, and ALP were significantly elevated, while total protein and LDH were significantly decreased in CMZ-exposed mice. CMZ injection led to significant increases in the levels of serum urea and creatinine. Moreover, the levels of serum IgA, IgG, and IgM in CMZ-treated mice were significantly lower than those in PBS-treated mice. Reduced lymphocyte proliferation capacity was observed in CMZ-treated mice. Interestingly, pre-treatment of vitamin C to CMZ-exposed mice mildly alleviated CMZ-induced immunobiochemical perturbations. Therefore, vitamin C mildly alleviated CMZ-induced immunobiochemical impacts, but it was not completely protective.
\end{abstract}

Conclusion: Further studies are needed to assess the relationships between antioxidants and CMZ-induced immunobiochemical perturbations.

Keywords: Clomazone, Immunobiochemical perturbations, Vitamin C, Alleviating role

\section{Background}

The immune system is regularly affected by chemical periodic stresses. Adverse environmental situations may chronically stress the animal's health, altering some of their immunobiochemical parameters and suppressing their immune and physiological responses (Miller et al., 2002). Pesticides are the major immunomodulators. Exposure to sublethal concentrations of pesticides is suspected of predisposing non-target species to diseases because of their immunobiochemical depressive effects (Dunier \& Siwicki, 1993; Richard, Peden, \& Williams, 1994).

Correspondence: nassefssd@science.tanta.edu.eg

Zoology Department, Faculty of Science, Tanta University, Tanta 31527, Egypt
One of the worldwide herbicides is clomazone (CMZ) that is employed for weed control. Comparatively, few data are available on its perturbations to non-target species (Jonsson, Maia, Ferreira, \& Ribeiro, 1998). In our previous work (Nassef, 2017), immunological and hematological perturbations in Swiss albino mice exposed to CMZ at concentration of $46 \mu \mathrm{M} / \mathrm{kg}$ had been reported. Exposure of organisms to contaminants such as CMZ can cause biological changes that can be used as indicators of environmental chemicals risks. Among biological changes, immunobiochemical parameters are considered potential biomarkers of chemical exposure (Van der Oost, Beyer, \& Vermeulen, 2003). The effects of pesticides have been observed in the changes of body weight gain, relative weight 
of immune-related organs (spleen and thymus), renal and liver functions, and contents of immunoglobulin (Ig) isotypes (IgA, IgE, and IgM).

Studies on non-target species showed reduction in final body weight by treatment with herbicide 2,4-D dimethylamine salt (DMA) (Salbego et al., 2010; Menezes et al., 2015) that may be due to changes in their metabolic pathways due to herbicide stress (Fonseca et al., 2008). Decreases in the absolute and relative weights of the spleen and thymus were observed in mice treated with atrazine (Filipov, Pinchuk, Boyd, \& Crittenden, 2005; Karrow et al., 2005; Zhang et al., 2011) that may be associated with the inhibition of lymphocyte proliferation and/or the increase of their death (Kamath, Xu, Nagarkatti, \& Nagarkatti, 1997; Vandebriel, Spiekstra, Hudspith, Meredith, \& Van Loveren, 1999).

Changes in urea and creatinine concentrations were used as markers of renal function due to chemical stress (Donadio, Lucchesi, Tramonti, \& Bianchi, 1997). Pesticides such as glyphosate and cypermethrin induced nephrotoxicity in mice which was evidenced by the rise in serum urea and creatinine levels that may be attributed to renal cell damage due to accumulation of these chemicals in the renal nephrons (Manzoor, Mehboob, \& Naveed, 2016).

Increases in the contents of liver enzymes such as alanine aminotransferase (ALT), aspartate aminotransferase (AST), and alkaline phosphatase (ALP) may be a sensible indicator of cellular liver damage caused by pesticide exposure (Gholami-Seyedkolaei, Mirvaghefi, Farahmand, \& Kosari, 2013). Sharma, Bashir, Rshad, Gupta, and Dogra (2005) reported a significant increase in AST, ALT, and ALP activities in pesticide-treated rats that may be due to increase in the secretory activities of the hepatocyte cells resulted from the disturbance in their transport function and membrane permeability as a result of pesticide-induced hepatic injury that causes the leakage of AST, ALT, and ALP from hepatocytes into the blood (Abdulaziz \& Hristev, 1996; Fan et al., 2009; Murussi et al., 2016; Yousef, Abbassi, \& Yacout, 1999).

Lactate dehydrogenase (LDH) is a cytoplasmic enzyme that is used clinically to diagnose cell injury; as such, it is a useful marker for toxic chemical exposure. Injection of mice with the pesticide diazinon resulted in reduction in the LDH level (Shokrzadeh et al., 2012) that may be resulted from failure in the antioxidant defense system to protect against free radicals and tissue oxidative damage (Salehi \& Jafary, 2010). Changes in total protein content can be considered as a diagnostic tool for physiological disorders due to chemical poisoning (Canli, 1996; Jacobs, Carmichael, \& Cavanagh, 1977) that might be due to a breakdown of protein into free amino acid (Sakr, Mahran, \& Abo-Elyazid, 2005) or destruction of cellular function and consequent impairment in protein synthetic machinery (David, Mushigeri, Shivakumar, \& Philip, 2004; Gokcimen et al., 2007).
The Ig isotypes (IgA, IgG, and IgM) play a crucial role in the immune system's defense mechanisms in response to exposure to a foreign invader such as toxins and toxic agents (Von König, Finger, \& H'Ormaycht, 1979). Pesticide administration may have a suppression effect on the secretion mechanism or specific response activity of Ig isotypes that was accompanied with the atrophy of immune-related organs (spleen and thymus) (Insel, Amstey, Woodin, \& Pichichero, 1994; Nimmerjahn \& Ravetch, 2008).

Antioxidant properties of vitamin $C$ could enhance immunity against pesticide effects by preserving the functional and structural integrity of important immune cells (Chew, 1995) and attenuate the pesticide-induced imunobiochemical perturbations by inactivating damaging free radicals produced through normal cellular activity and from various chemical stresses (Kalender, Uzunhisarcikli, Ogutcu, Acikgoz, \& Kalender, 2006; Jurczuk, Brzóska, \& Moniuszko-Jakoniuk, 2007; Uzunhisarcikli et al., 2007; Verma, Mehta, \& Srivastava, 2007; Ogutcu, Suludere, \& Kalender, 2008).

To complete searching the possible immunological perturbations of CMZ which we reported in our recent publication (Nassef, 2017), the objectives of this work were to investigate the probable immunobiochemical perturbations induced by herbicide CMZ and to evaluate the alleviating role of vitamin $C$ against these perturbations in male Swiss albino mice.

\section{Methods \\ Mice}

Male Swiss albino mice (weighting 25-34 g), purchased from the National Research Centre, Cairo, Egypt, were kept in a specific pathogen-free and well-ventilated animal facility in accordance with the standard guide for the care and use of laboratory animals. The mice were quarantined for 1 week (12-h light/dark cycle, $22 \pm 2{ }^{\circ} \mathrm{C}$, $60-65 \%$ relative humidity) before experimentation. The mice were given pellet food and water ad libitum.

\section{Chemicals and reagents}

Clomazone (CMZ; FMC Corporation, Philadelphia, USA) and L-ascorbic acid (vitamin C; Carlo Erba, Milano, Italy) were dissolved in phosphate-buffered saline (PBS) at desired experimental doses.

\section{Treatment plan}

The mice were exposed to PBS, CMZ [46 $\mu \mathrm{M} / \mathrm{kg} ; 1 / 20$ of the $96-\mathrm{h} \mathrm{LD}_{50}$ for an intraperitoneal (i.p.) dose; Nassef, 2017], and/or vitamin C (1136 $\mu \mathrm{M} / \mathrm{kg}$; Uzun, Kalender, Durak, Demir, \& Kalender, 2009). The mice were divided into four groups of ten animals each. Group 1 i.p. administrated PBS as a control group, Group 2 i.p. inoculated with vitamin $C(1136 \mu \mathrm{M} / \mathrm{kg})$, Group 3 i.p. injected with CMZ $(46 \mu \mathrm{M} / \mathrm{kg})$, and Group 4 i.p. injected with vitamin 
C $(1136 \mu \mathrm{M} / \mathrm{kg}) 30 \mathrm{~min}$ prior to i.p. administration of CMZ $(46 \mu \mathrm{M} / \mathrm{kg})$, daily 4 weeks. By the end of the treatment, five mice from each group were euthanized by cervical dislocation at fasting state. Prior to the scarifying, final body weights of the mice were recorded and blood samples were collected for immunobiochemical analyses. The thymus and spleen were aseptically removed and weighted.

\section{Body weight gain and immune-related organs' relative weight}

Final body weight of the mice in all experimental groups was recorded. The spleen and thymus were removed aseptically and weighted, and their relative body weights (ROW) were calculated according to Aniagu et al. (2005) using the following formula: ROW $=$ [absolute organ weight (g)/body weight of mice on sacrifice day $(\mathrm{g})] \times 100$. Percentage weight gains of mice $(W G \%)$ were calculated according to Tukmechi, Rezaee, Nejati, and Sheikhzadeh (2014) using the following formula: WG\% = (final body weight - initial body weight $) \times 100 /$ initial body weight).

\section{Preparation of sera samples}

Five mice from each group were euthanized by cervical dislocation at fasting state. Blood samples were collected from the retro-orbital plexus in plastic test tubes and allowed to stand for $3 \mathrm{~h}$ to ensure complete clotting. The clotted blood samples were centrifuged at $3000 \mathrm{rpm}$ for $10 \mathrm{~min}$, and the clear sera samples were aspirated off and stored frozen at $-80{ }^{\circ} \mathrm{C}$ for immunobiochemical analyses.

\section{Biochemical analyses}

The following parameters were determined calorimetrically by employing the standard ready-to-use kits and methods of Human (Human Gesellschaft für Biochemica and Diagnostica MBH, Germany) using a fully automated biochemistry analyzer (Vitalab Selectra E, Germany): AST $(\mathrm{U} / \mathrm{l})$, ALT (U/l), ALP $(\mathrm{U} / \mathrm{l})$, total protein $(\mathrm{g} / \mathrm{dl})$, creatinine $(\mathrm{mg} / \mathrm{dl})$, and urea $(\mathrm{mg} / \mathrm{dl})$. LDH was measured using kits supplied by Diamond Diagnostics according to the method of Cobaud and Warblewski (1958). The manufacturer's instructions for each biochemical parameter were strictly followed in the course of the investigations.

\section{Enzyme-linked immunosorbent assay for serum immunoglobulin isotypes}

Serum levels of IgA, IgG, and IgM in exposed mice were evaluated by using enzyme-linked immunosorbent assay (ELISA) as described by Arce, Nawar, Muehlinghaus, Russell, and Connell (2007) and Keggan, Freer, Rollins, and Wagner (2013). Briefly, microtiter plates (Nunc, Roskilde, Denmark) were coated with $4 \mu \mathrm{g} / \mathrm{ml}$ of goat anti-mouse Ig isotype-specific antibodies (Southern Biotechnology, Birmingham, AL) in carbonate coating buffer ( $1 \mathrm{M} \mathrm{NaHCO}_{3}, 1 \mathrm{M} \mathrm{Na}_{2} \mathrm{CO}_{3}, \mathrm{pH}$ 9.6) and incubated overnight at $4{ }^{\circ} \mathrm{C}$. Plates were washed four times with PBS, 0.05\% TWEEN (PBST, Sigma-Aldrich, St. Louis, $\mathrm{MO}$ ) and then incubated with different dilutions of sera obtained from mice of control groups or from mice i.p. injected with vitamin $\mathrm{C}, \mathrm{CMZ}$, or $\mathrm{CMZ}$ plus vitamin $\mathrm{C}$, and the plates were incubated overnight at $4{ }^{\circ} \mathrm{C}$. The plates were again washed with PBST and incubated at room temperature for $4 \mathrm{~h}$ with the appropriate alkaline phosphatase-conjugated goat anti-mouse Ig isotypespecific antibodies (Southern Biotechnology) diluted 1:10,000. The plates were washed with PBST and incubated $15 \mathrm{~min}$ in the dark with substrate buffer $(33.3 \mathrm{mmol}$ citric acid, $66.7 \mathrm{mmol} \mathrm{NaH} \mathrm{PO}_{4}, \mathrm{pH}$ 5.0), combined with

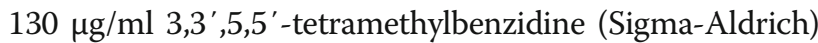
and $0.012 \%$ hydrogen peroxide. Color reactions were terminated by adding $100 \mu \mathrm{l}$ of $2.0 \mathrm{M} \mathrm{NaOH}$ to each well. The optical density of the color reaction mixture was assessed using an automatic on a multiwall scanning spectrophotometer (Biotek, Winooski, VT) at 450-nm absorbance. Concentrations of $\mathrm{Ig}$ isotypes $(\mu \mathrm{g} / \mathrm{ml})$ were calculated by the interpolation of calibration curves generated by using a mouse Ig reference serum (ICN Biomedicals, Aurora, OH).

\section{In vitro lymphocyte proliferation assay}

Lymphocyte preparation and treatment: Peripheral blood mononuclear cells (PBMC) were separated from the blood sample of Swiss albino mice according to Goyarts, Dänicke, Tiemann, and Rothkötter (2006). Briefly, $3 \mathrm{ml}$ of heparinized blood were layered over a Ficoll-Histopaque 1077 (Sigma, Mumbai, India) and centrifuged (500 $\times$ g, $20 \mathrm{~min}, 4^{\circ} \mathrm{C}$ ). The buffy cellular layer at the interface was collected and washed three times (centrifugation $300 \times g$, $10 \mathrm{~min}, 4{ }^{\circ} \mathrm{C}$ ) in RPMI-1640 medium (Gibco/BRL, USA), then cells were resuspended in complete RPMI-1640 medium and counted. Viable cells were counted using trypan blue dye exclusion technique. Cells $\left(1 \times 10^{5}\right.$ cells/well $)$ were cultured in a 96-well flat-bottomed tissue culture plate. For lymphoproliferation stimulation, triplicate wells were treated with $5 \mu \mathrm{g} / \mathrm{ml}$ mitogen phytohemagglutinin (PHA, Sigma-Aldrich) then incubated $\left(37^{\circ} \mathrm{C}, 5 \% \mathrm{CO}_{2}\right.$ for 24 h (Wichmann, Herbarth, \& Lehmann, 2002). After incubation, test compounds were added to each well: vitamin C (113.6 $\mu \mathrm{M} /$ well; Uzun et al., 2009), CMZ (4.6 $\mu \mathrm{M} /$ well; $1 / 200$ of the $96-\mathrm{LD}_{50}$ for an i.p.; Nassef, 2017), or a combination of CMZ and vitamin $\mathrm{C}$ with the same dose of each, then the plate was incubated for $48 \mathrm{~h}$ under the same incubation conditions.

MTT assay: After 48-h incubation, lymphocyte proliferation was determined by MTT (3-(4,5-dimethyl-2-thiazolyl)2,5-diphenyl-2H-tetrazolium)-based assay (Mosmann, 1983): $2 \mathrm{mg} / \mathrm{mL}$ of MTT were added to each well and incubated at $28{ }^{\circ} \mathrm{C}$ for $24 \mathrm{~h}$. The MTT-formazan crystals, 
which are formed only by live cells, were dissolved in $100 \mu \mathrm{l}$ dimethyl sulfoxide (DMSO), enabling the optical density of each well to be measured using an ELISA reader at a transmitting wavelength of $570 \mathrm{~nm}$. Stimulation index (SI) was investigated using the following formula:

$$
\mathrm{SI}=\mathrm{OD}_{\text {mitogen-stimulated test }} / \mathrm{OD}_{\text {mitogen-unstimulated test }}
$$

\section{Data analysis}

The results were expressed as mean \pm SE. Statistical analysis was done using Student's $t$ test. A difference of $P \leq 0.05$ was considered statistically significant.

\section{Results}

Generally, present data revealed significant immunobiochemical changes induced by the inoculation of CMZ, vitamin $\mathrm{C}$, and their combination in male Swiss albino mice. Interestingly, vitamin $\mathrm{C}$ pre-treatment to CMZtreated mice mildly alleviates some of these changes.

The impacts of CMZ, vitamin $\mathrm{C}$, and their combination on body weight gain are indicated in Table 1. The obtained data revealed a significant decrease in body weight gain in vitamin C-, CMZ- and CMZ plus vitamin $\mathrm{C}$-treated mice as compared to PBS-treated mice. Comparing to its values in vitamin $\mathrm{C}$-treated mice, the results revealed a significant change in body weight gain in CMZ- and CMZ plus vitamin C-treated mice. There were no statistically significant changes in the weight gain in CMZ plus vitamin C-treated mice, when compared to the CMZ-treated group (Table 1).

The effects of CMZ, vitamin $\mathrm{C}$, and their combination on relative weights of immune-relative organs (spleen and thymus) are illustrated in Table 2. Results showed that $\mathrm{CMZ}$ and CMZ plus vitamin $\mathrm{C}$ treatments resulted in significant decrease in the spleen and thymus relative weights, while vitamin $C$ treatment resulted in significant increase in the spleen and thymus relative weights comparing to PBS-treated mice, while co-treatment of vitamin C prior to CMZ injection by $30 \mathrm{~min}$ significantly elevated this decrease as compared to the CMZ-treated group. Vitamin Ctreated group showed no significant effects in relative weights of either spleen or thymus when compared to
PBS-treated mice. Comparing to vitamin C-treated mice, CMZ-inoculated mice showed significant decreases in relative weights of the spleen and thymus. Similarly, thymus relative weights were significantly decreased in CMZ plus vitamin $\mathrm{C}$-treated mice when compared with the vitamin C-treated mice (Table 2).

In terms of serum biochemical analysis as shown in Table 3, CMZ- and CMZ plus vitamin C-treated mice had significantly higher values for ALT, AST, and ALP than in the PBS-treated group. Similarly, ALT, AST, and ALP values were significantly increased in CMZ-treated mice when compared with the vitamin $C$-treated mice. Pre-treatment of vitamin $\mathrm{C}$ to $\mathrm{CMZ}$-treated mice resulted in significant depletion of the higher values of ALT, AST, and ALP (Table 3). There were no significant changes in the values of ALT, AST, or ALP in vitamin C-treated mice compared to PBS-treated mice.

Vitamin C-inoculated mice did not differ significantly from the PBS-treated mice in terms of urea or creatinine values (Table 4). Urea and creatinine showed significant elevations in CMZ- and CMZ plus vitamin C-treated mice comparing to PBS- or vitamin C-treated mice, while administration of $\mathrm{CMZ}$ plus vitamin $\mathrm{C}$ significantly reduced this elevation of urea and creatinine values compared to the CMZ-treated group. Similarly, compared to their values in the vitamin C-treated group, there were significant elevations in urea concentrations (CMZ-treated mice) and creatinine concentrations (CMZ- and CMZ plus vitamin C-treated mice) (Table 4).

The Ig isotype production activity of CMZ, vitamin C, and their combination in exposed Swiss albino mice is shown in Table 5. Data revealed that CMZ injection caused significant decrease in the concentration of IgA, IgG, and IgM, while administration of CMZ plus vitamin $\mathrm{C}$ revealed significant decrease in the content of IgA and IgM when compared to the PBS-treated group. Comparing to vitamin $\mathrm{C}$-treated mice, CMZ- and $\mathrm{CMZ}$ plus vitamin $\mathrm{C}$-treated mice recorded significant depletion in the level of IgA, IgG, or IgM. The vitamin C-treated group did not differ significantly from the control group in terms of IgA, but recorded significant elevation in terms of IgA or IgM. Pre-treatment of vitamin C to CMZ-treated mice resulted in significant elevation of IgA and IgM concentrations (Table 5).

Table 1 Changes in body weight and percentage of body weight gain of male Swiss albino mice treated with PBS, vitamin C (1136 $\mu$ M/ $\mathrm{kg}), \mathrm{CMZ}(46 \mu \mathrm{M} / \mathrm{kg})$, or a combination of CMZ and vitamin C with the same dose of each intraperitoneally (i.p.) daily over 4 weeks

\begin{tabular}{llll}
\hline Experimental group & Initial body weight (g) & Final body weight (g) & Weight gain (\%) \\
\hline PBS & $28.20 \pm 0.59$ & $40.31 \pm 0.38$ & $43.27 \pm 1.80$ \\
Vitamin C & $30.00 \pm 0.59$ & $39.00 \pm 0.97$ & $30.12 \pm 2.71^{*}$ \\
CMZ & $32.00 \pm 0.55$ & $36.12 \pm 0.69$ & $12.91 \pm 1.23^{* \$}$ \\
CMZNitamin C & $31.00 \pm 1.02$ & $34.51 \pm 1.06$ & $11.43 \pm 1.06^{* \$}$ \\
\hline
\end{tabular}

Data were represented as mean \pm SE $(n=10)$

*Statistically significant vs. PBS-treated group; ${ }^{\text {s }}$ statistically significant vs. vitamin C-treated group. $P \leq 0.05$ 
Table 2 Changes in the weights (absolute and relative) of immune-related organs (spleen and thymus) of male Swiss albino mice

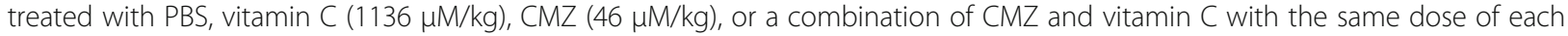
intraperitoneally (i.p.) daily over 4 weeks

\begin{tabular}{|c|c|c|c|c|}
\hline \multirow{2}{*}{$\begin{array}{l}\text { Experimental } \\
\text { groups }\end{array}$} & \multicolumn{2}{|l|}{ Spleen } & \multicolumn{2}{|l|}{ Thymus } \\
\hline & Absolute weight (g) & Relative weight & Absolute weight (g) & Relative weight \\
\hline PBS & $0.263 \pm 0.019$ & $0.650 \pm 0.044$ & $0.129 \pm 0.002$ & $0.321 \pm 0.006$ \\
\hline Vitamin C & $0.273 \pm 0.013$ & $0.698 \pm 0.029$ & $0.136 \pm 0.001$ & $0.350 \pm 0.009^{*}$ \\
\hline CMZ & $0.188 \pm 0.008$ & $0.523 \pm 0.025^{* \$}$ & $0.091 \pm 0.004$ & $0.251 \pm 0.012^{* \$}$ \\
\hline CMZ/vitamin C & $0.214 \pm 0.006$ & $0.624 \pm 0.025^{\#}$ & $0.099 \pm 0.004$ & $0.288 \pm 0.011^{* \$ \#}$ \\
\hline
\end{tabular}

Data were represented as mean \pm SE $(n=10)$

PBS phosphate buffer saline, CMZ clomazone

${ }^{*}$ Statistically significant vs. PBS-treated group; ${ }^{\$}$ statistically significant vs. vitamin C-treated group; ${ }^{\#}$ statistically significant vs. CMZ-treated group. $P \leq 0.05$

The effect of CMZ, vitamin C, or their combinations on mitogen-induced lymphoproliferation was evaluated in lymphocytes using MTT assay (Table 6). Current data indicated that the lymphocytes from mice exposed to $\mathrm{CMZ}$ alone showed a significant reduction in proliferation index (SI), while pre-treatment of vitamin $C$ to CMZ-treated mice revealed non-significant reduction in SI compared with the PBS-treated group. Contrarily, vitamin $\mathrm{C}$ alone treatment resulted in non-significant increase in lymphocyte SI compared to PBS-treated mice (Table 6).

The impacts of CMZ, vitamin $\mathrm{C}$, and their combination on the serum level of total protein and LDH in Swiss albino mice are indicated in Tables 7 and 8, respectively. Data revealed that CMZ and CMZ plus vitamin $C$ treatments caused a significant decrease in the concentration of total protein (Table 7) and LDH (Table 8) when compared to the PBS-treated group. Pre-treatment of vitamin $C$ to CMZ-treated mice significantly modulated the depletion in total protein value (Table 7 ).

The levels of total protein and LDH in mice treated with CMZ alone or CMZ plus vitamin were significantly lower than their values in vitamin C-treated group (Tables 7 and 8 ).

Table 3 Changes in the level of serum liver biochemical markers; transaminase activity (AST and ALT) and alkaline phosphatase activity (ALP) of male Swiss albino mice treated with PBS, vitamin $C(1136 \mu \mathrm{M} / \mathrm{kg}), C M Z(46 \mu \mathrm{M} / \mathrm{kg})$, or a combination of CMZ and vitamin $C$ with the same dose of each intraperitoneally (i.p.) daily over 4 weeks

\begin{tabular}{llll}
\hline Experimental groups & ALT (U/I) & AST (U/I) & ALP (U/I) \\
\hline PBS & $60.6 \pm 4.04$ & $91.0 \pm 5.80$ & $167.20 \pm 6.73$ \\
Vitamin C & $62.4 \pm 4.58$ & $94.0 \pm 6.24$ & $172.20 \pm 4.91$ \\
CMZ & $82.0 \pm 2.86^{* \$}$ & $120.0 \pm 2.00^{* \$}$ & $201.40 \pm 4.10^{* \$}$ \\
CMZ/vitamin C & $73.0 \pm 3.72^{* \#}$ & $106.2 \pm 3.99^{\#}$ & $179.80 \pm 4.94^{\#}$
\end{tabular}

Data were represented as mean \pm SE $(n=5)$

$P B S$ phosphate buffer saline, $C M Z$ clomazone

*Statistically significant vs. PBS-treated group; ${ }^{\text {s}}$ statistically significant vs. vitamin

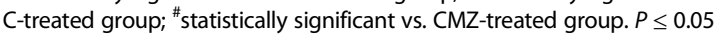

\section{Discussion}

Immunobiochemical change is considered one of the good indicators for toxicity evaluation of herbicides to estimate the potential the animals' health (Brodkin, Madhoun, Rameswaran, \& Vatnick, 2007; Salbego et al., 2010). The impacts of pesticides had been revealed in the immunobiochemical perturbations such as changes in body weight gain, atrophy and relative weights of immune-related organs, renal and liver functions, and concentrations of Ig isotypes (Fournier, Friborg, Girard, Mansour, \& Krzystyniak, 1992; Filipov et al., 2005; Brodkin et al., 2007).

In the present study, a significant decrease in body weight gain was monitored in the mice group injected with CMZ alone or CMZ plus vitamin C. Similar responses were observed by Menezes et al. (2015) who monitored a reduction in the final weight and specific growth rate of silver catfish exposed to the herbicide 2,4-D dimethylamine salt (DMA) that may be due to CMZ long-term exposure that affects the growth of the exposed animal by altering its metabolism efficacy resulting in the overall increased degeneration of lipids and proteins (Fonseca et al., 2008; Menezes et al., 2015; Dahdouh, Attalah, Djabar, \& Kechrid, 2016).

Current results revealed a significant decrease in the mean of mice spleen and thymus relative weights by

Table 4 Changes in the level of serum kidney biochemical markers; urea and creatinine of male Swiss albino mice treated with

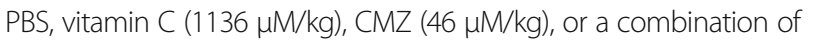
CMZ and vitamin $C$ with the same dose of each intraperitoneally (i.p.) daily over 4 weeks

\begin{tabular}{lll}
\hline Experimental groups & Urea $(\mathrm{mg} / \mathrm{dl})$ & Creatinine $(\mathrm{mg} / \mathrm{dl})$ \\
\hline PBS & $34.60 \pm 3.26$ & $0.41 \pm 0.01$ \\
Vitamin C & $33.20 \pm 2.51$ & $0.42 \pm 0.01$ \\
CMZ & $49.60 \pm 2.15^{* \$}$ & $0.57 \pm 0.01^{* \$}$ \\
CMZ/vitamin C & $39.80 \pm 0.91^{* \$ \#}$ & $0.49 \pm 0.01^{* \$ \#}$ \\
\hline
\end{tabular}

Data were represented as mean $\pm \mathrm{SE}(n=5)$

$P B S$ phosphate buffer saline, $C M Z$ clomazone

*Statistically significant vs. PBS-treated group; ${ }^{\text {\$ }}$ statistically significant vs. vitamin

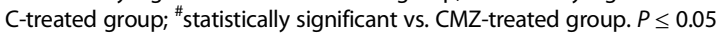


Table $\mathbf{5}$ Immunomodulatory activity in the serum of male Swiss albino mice treated with PBS, vitamin C $(1136 \mu \mathrm{M} / \mathrm{kg}), \mathrm{CMZ}$ $(46 \mu \mathrm{M} / \mathrm{kg})$, or a combination of $\mathrm{CMZ}$ and vitamin $\mathrm{C}$ with the same dose of each intraperitoneally (i.p.) daily over 4 weeks

\begin{tabular}{llll}
\hline Experimental groups & $\operatorname{lgA}(\mathrm{mg} / \mathrm{ml})$ & $\mathrm{lgG}(\mathrm{mg} / \mathrm{ml})$ & $\operatorname{lgM}(\mathrm{mg} / \mathrm{ml})$ \\
\hline PBS & $1.56 \pm 0.06$ & $3.21 \pm 0.10$ & $0.86 \pm 0.03$ \\
Vitamin C & $1.68 \pm 0.05^{*}$ & $3.40 \pm 0.22$ & $1.04 \pm 0.05^{*}$ \\
CMZ & $1.12 \pm 0.03^{* \$}$ & $2.61 \pm 0.07^{* \$}$ & $0.52 \pm 0.02^{* \$}$ \\
CMZ/vitamin C & $1.34 \pm 0.04^{* \$ \#}$ & $2.90 \pm 0.14^{\$}$ & $0.71 \pm 0.04^{* \$ \#}$
\end{tabular}

Data were represented as mean \pm SE $(n=5)$ PBS phosphate buffer saline, $C M Z$ clomazone *Statistically significant vs. PBS-treated group; ${ }^{\text {\$ }}$ statistically significant vs. vitamin C-treated group; ${ }^{\#}$ statistically significant vs. CMZ-treated group. $P \leq 0.05$

exposure to CMZ. Similar results were speculated by Zhang et al. (2011) in mice exposed to pesticide atrazine (200 and $400 \mathrm{mg} / \mathrm{kg}$ ) suggesting possible chemicalinduced apoptotic mechanism of splenic and thymic atrophy (Prater, Gogal, Blaylock, Longstreth, \& Holladay, 2002) that may be associated with the inhibition of lymphocyte proliferation and/or the increase of lymphocyte death in the spleen and thymus in response to herbicide stress (Kamath et al., 1997; Vandebriel et al., 1999).

A significant increase in ALT, AST, and ALP levels was recorded in the sera of mice treated with CMZ alone. This result was confirmed by the report of Sharma et al. (2005) who revealed a significant increase in AST, ALT, and ALP activities in pesticide-treated rats that may be due to increase in the secretory activities of the hepatocyte cells (Abdulaziz \& Hristev, 1996; Yousef et al., 1999). The disturbance in the transport function and membrane permeability of the hepatocytes as a result of pesticide-induced hepatic injury results in the leakage of AST, ALT, and ALP from cells into the blood (Fan et al., 2009; Murussi et al., 2016).

Proteins are involved in major physiological events, so its content evolution can be considered as a diagnostic tool for immunobiochemical disorders due to chemical poisoning (Canli, 1996; Jacobs et al., 1977). The present results showed a significant decrease in mice serum total protein and $\mathrm{LDH}$ in response to CMZ toxicity. In agreement with

Table 6 Ex vivo anti-proliferative effects of vitamin C (113.6 $\mu \mathrm{M} /$ well), clomazone (CMZ) (4.6 $\mu \mathrm{M} /$ well), or a combination of CMZ and vitamin $\mathrm{C}$ with the same dose of each for $48 \mathrm{~h}$ on murine lymphocytes

\begin{tabular}{ll}
\hline Experimental groups & Proliferation index \\
\hline PBS & $1.04 \pm 0.10$ \\
Vitamin C & $1.20 \pm 0.23$ \\
CMZ & $0.72 \pm 0.03^{*}$ \\
CMZ/vitamin C & $0.75 \pm 0.08$ \\
\hline
\end{tabular}

Data were represented as mean \pm SE $(n=5)$

$P B S$ phosphate buffer saline, $C M Z$ clomazone

*Statistically significant vs. PBS-treated group $(P \leq 0.05)$
Table 7 Changes in the level of serum total protein of male Swiss albino mice treated with PBS, vitamin C (1136 $\mu \mathrm{M} / \mathrm{kg})$, CMZ (46 $\mu \mathrm{M} / \mathrm{kg})$, or a combination of CMZ and vitamin C with the same dose of each intraperitoneally (i.p.) daily over 4 weeks

\begin{tabular}{ll}
\hline Experimental groups & Total protein $(\mathrm{mg} / \mathrm{dl})$ \\
\hline PBS & $7.52 \pm 0.15$ \\
Vitamin C & $7.60 \pm 0.19$ \\
CMZ & $6.40 \pm 0.12^{* \$}$ \\
CMZNitamin C & $7.02 \pm 0.14^{* \# \$}$
\end{tabular}

Data were represented as mean $\pm \operatorname{SE}(n=5)$

$P B S$ phosphate buffer saline, $C M Z$ clomazone

${ }^{*}$ Statistically significant vs. PBS-treated group; ${ }^{\$}$ statistically significant vs. vitamin

C-treated group; ${ }^{\#}$ statistically significant vs. CMZ-treated group. $P \leq 0.05$

the present data, Canli (1996) and Reddy and Bhagyalakshmi (1994) report a decrease in total protein content in fish during mercury exposure. Pesticide-induced tissue destruction and hepatocyte apoptosis might be the most important agent responsible of reducing the synthesis of total protein in the liver (Gokcimen et al., 2007). Similar to our results, a significant decrease in mice $\mathrm{LDH}$ in response to pesticide diazinon toxicity was reported by Shokrzadeh et al. (2012) that may be related to a failure in the antioxidant defense system to protect against free radicals and tissue oxidative damage (Salehi \& Jafary, 2010).

There were significant down-regulated activities of IgA, IgG, and IgM in response to CMZ treatment. Review about the impacts of pesticide exposure on the level of Ig isotypes is very rare and argumentative. Ig isotypes play a role in the immune system's defense in response to exposure to a foreign invader such as toxins and toxic agents (Von König et al., 1979). Pesticide administration may have a suppression effect on the secretion mechanism or specific response activity of Ig isotypes that was accompanied with atrophy of immune-related organs (Insel et al., 1994; Nimmerjahn \& Ravetch, 2008).

Investigations of serum urea and creatinine level were used as markers of renal function due to chemical stress (Donadio et al., 1997). The current study revealed an increase in the level of urea and creatinine due to CMZ

Table 8 Changes in the level of LDH of male Swiss albino mice treated with PBS, vitamin C (1136 $\mu \mathrm{M} / \mathrm{kg}), \mathrm{CMZ}(46 \mu \mathrm{M} / \mathrm{kg})$, or a combination of $\mathrm{CMZ}$ and vitamin $\mathrm{C}$ with the same dose of each intraperitoneally (i.p.) daily over 4 weeks

\begin{tabular}{ll}
\hline Experimental groups & LDH (U/I) \\
\hline PBS & $1269 \pm 101$ \\
Vitamin C & $1169 \pm 52$ \\
CMZ & $890 \pm 82^{* \$}$ \\
CMZ/vitamin C & $834 \pm 40^{* \$}$
\end{tabular}

Data were represented as mean $\pm \operatorname{SE}(n=5)$

PBS phosphate buffer saline, $C M Z$ clomazone, $L D H$ lactate dehydrogenase *Statistically significant vs. PBS-treated group; ${ }^{\zeta}$ statistically significant vs. vitamin C-treated group. $P \leq 0.05$ 
stress. Our study draws a parallel with the research work of Manzoor, Mehboob, and Naveed (2016) who observed that pesticides such as glyphosate and cypermethrin induced nephrotoxicity in mice which was evidenced by a rise in serum urea and creatinine levels that may be attributed to renal cell damage due to accumulation of these pesticides in the renal nephrons.

The ex vivo cell proliferative response is estimated by the stimulation index (SI) and is one of the most acceptable protocols for investigation of the immunocompetence of chemical-treated lymphocytes after mitogenic stimulation (Blohm, Siegl, \& KÖllner, 2003). Thus, a reduction in the value of SI may be an indication of a decrease of the immunocompetence of the organism. Reduced cellular proliferation was observed in Balb/C mice lymphocytes (Sakazaki, Ueno, Uematani, Utsumi, \& Nakamuro, 2001). The inhibitory effect of pesticide on cell proliferation is likely to reflect the ability of these chemicals to inhibit protein synthesis through binding to ribosomal peptidyl transferase (Corrier, 1991; Shifrin \& Anderson, 1999).

The results obtained herein revealed that vitamin $\mathrm{C}$ coadministration partially diminished the immunobiochemical perturbations resulted from CMZ treatment. Vitamin $\mathrm{C}$ is known to be an antioxidant that can attenuate the pesticide-induced physiological and biochemical perturbations due to the scavenging of free radicals produced through normal cellular activity and from various chemical stresses (Kalender et al., 2006; Jurczuk et al., 2007). It has been suggested that the antioxidant property of vitamin $C$ could enhance immunity against pesticide toxicity by preserving the functional and structural integrity of important immune cells. (Chew, 1995).

\section{Conclusions}

In summary, CMZ treatment can induce immunobiochemical perturbations in exposed mice and vitamin $C$ therapy mildly alleviates some of these perturbations. Further studies are needed in order to assess the possible relationships between antioxidants and CMZ-induced immunobiochemical perturbations.

\section{Funding}

The research reported is funded by the private partnership.

\section{Availability of data and materials}

The datasets generated and analyzed during the current study are available from the corresponding author on reasonable request.

\section{Authors' contributions}

The author was responsible for the idea and the designing of the study, execution of the experiments, carrying out the data analysis, and writing and revising the manuscript.

\section{Ethics approval and consent to participate}

This study was approved by the Social Science Ethical Committee of the Faculty of Science, Tanta University and complied with the Egyptian Code of Conduct for Scientific Practice, National Research Centre, Egypt.
Consent for publication

Not applicable.

\section{Competing interests}

The author declares that he has no competing interests.

\section{Publisher's Note}

Springer Nature remains neutral with regard to jurisdictional claims in published maps and institutional affiliations.

Received: 21 June 2017 Accepted: 16 August 2017

Published online: 26 September 2017

\section{References}

Abdulaziz, M., \& Hristev, H. (1996). Serum aminotransferase, alkaline transferase and lactate dehydrogenase responses to oral consecutive doses of cyano-3 alpha-phenoxy benzyl pyrethroids on sheep. Bulgarian Journal of Agricultural Science, 2, 661-666.

Aniagu, S. O., Nwinyi, F. C., Akumka, D. D., Ajoku, G. A., Dzarma, S., Izebe, K. S., Ditse, M., Nwaneri, P. E., Wambebe, C., \& Gamaniel, K. (2005). Toxicity studies in rats fed nature cure bitters. African Journal of Biotechnology, 4(1), 72-78.

Arce, S., Nawar, H. F., Muehlinghaus, G., Russell, M. W., \& Connell, T. D. (2007). In vitro induction of immunoglobulin A (IgA)-and IgM-secreting plasma blasts by cholera toxin depends on T-cell help and is mediated by CD154 upregulation and inhibition of gamma interferon synthesis. Infection and Immunity, 75(3), 1413-1423.

Blohm, U., Siegl, E., \& KÖllner, B. (2003). Rainbow trout (Oncorhynchus mykiss) slgM-leucocytes secrete an interleukin-2 like growth factor after mitogenic stimulation in vitro. Fish \& Shellfish Immunology, 14, 449-466.

Brodkin, M. A., Madhoun, H., Rameswaran, M., \& Vatnick, I. (2007). Atrazine is an immunedisruptor in adult northern leopard frogs (Rana pipiens). Environmental Toxicology and Chemistry, 26, 80-84.

Canli, M. (1996). Effects of mercury, chromium and nickel on glycogen reserves and protein levels in tissues of cyprinuscaprio. Turkish Journal of Zoology, 20, 161-168.

Chew, B. P. (1995). Antioxidant vitamins affect food animal immunity and health. The Journal of Nutrition, 125, 18045-18085.

Cobaud, P. A., \& Warblewski, T. (1958). Colorimeteric determination of lactic aciddehydrogenase of body fluids. The American Journal of Pathology, 10, 234-236.

Corrier, D. E. (1991). Mycotoxicosis: Mechanisms of immunosuppression. Veterinary Immunology and Immunopathology, 30, 73-87.

Dahdouh, F., Attalah, S., Djabar, M., \& Kechrid, Z. (2016). Effect of the joint supplementation of vitamin $\mathrm{c}$ and vitamin e on nickel heamatotoxicity and nephrotoxicity in male swiss albino mice. International Journal of Pharmacy and Pharmaceutical Sciences, 8(6), 234-239.

David, M., Mushigeri, S. B., Shivakumar, R., \& Philip, G. H. (2004). Response of Cyprinuscarpio (Linn) to sublethal concentration of cypermethrin: Alterations in protein metabolic profiles. Chemosphere, 56(4), 347-352.

Donadio, C., Lucchesi, A., Tramonti, G., \& Bianchi, C. (1997). Creatinineclearance predicted from body cell mass is a good indicatorof renal function. Kidney International. Supplement, 63, 166-168.

Dunier, M., \& Siwicki, A. K. (1993). Effect of pesticides and other organic pollutants in the aquatic environment on immunity of fish: A review. Fish \& Shellfish Immunology, 3, 423-438.

Fan, G., Tang, J. J., Bhadauria, M., Nirala, S. K., Dai, F., Zhou, B., Li, Y., \& Liu, Z. L. (2009). Resveratrol ameliorates carbon tetrachloride-induced acute liver injury in mice. Environmental Toxicology and Pharmacology, 28(3), 350-356.

Filipov, N. M., Pinchuk, L. M., Boyd, B. L., \& Crittenden, P. L. (2005). Immunotoxic effects ofshort-term atrazine exposure in young male C57BL/6 mice. Toxicological Sciences, 86, 324-332

Fonseca, M. B., Glusczak, L., Moraes, B. S., Menezes, C. C., Pretto, A., Tierno, M. A. Zanella, R., Gonçalves, F. F., \& Loro, V. L. (2008). The 2,4-D herbicide effects on acetylcholinesterase activity andmetabolic parameters of piava freshwater fish (Leporinus obtusidens). Ecotoxicology and Environmental Safety, 69, 416-420.

Fournier, M., Friborg, J., Girard, D., Mansour, S., \& Krzystyniak, K. (1992). Limitedimmunotoxic potential of technical formulation of the herbicide atrazine (AAtrex) in mice. Toxicology Letters, 60, 263-274.

Gholami-Seyedkolaei, S. J., Mirvaghefi, A., Farahmand, H., \& Kosari, A. A. (2013). Effect of a glyphosate-based herbicidein Cyprinus carpio: Assessment of 
acetylcholinesteraseactivity, hematological responses and serum biochemicalparameters. Ecotoxicology and Environmental Safety, 98, 135-141.

Gokcimen, A., Gulle, K., Demirin, H., Bayram, D., Koca, A., \& Altuntas, I. (2007). Effect ofdiazinon at different doses on rat liver and pancreastissues. Pesticide Biochemistry and Physiology, 87, 103-108.

Goyarts, T., Dänicke, S., Tiemann, U., \& Rothkötter, H. J. (2006). Effect of the Fusarium toxin deoxynivalenol (DON) on $\lg A$, IgM and $\lg G$ concentrations and proliferation of porcine blood lymphocytes. Toxicology In Vitro, 20(6), 858-867

Insel, R. A., Amstey, M., Woodin, K., \& Pichichero, M. (1994). Maternal immunization to preventinfectious diseases in the neonate or infant. International Technol Assess Health Care., 10, 143-153.

Jacobs, J. M., Carmichael, N., \& Cavanagh, J. B. (1977). Ultrastructural changes in the nervous system of rabbits poisoned with methyl mercury. Toxicology and Applied Pharmacology, 39(2), 249-261.

Jonsson, C. M., Maia, A. H. N., Ferreira, C. J. A., \& Ribeiro, E. O. (1998). Risk assessment of the herbicide clomazone in the aquatic life. Verhandlungen des Internationalen Verein Limnologie., 26, 1724-1726.

Jurczuk, M., Brzóska, M. M., \& Moniuszko-Jakoniuk, J. (2007). Hepatic and renal concentrations of vitamins $E$ and $C$ in lead- and ethanol-exposed rats. An assessment of their involvement in the mechanisms of peroxidative damage. Food and Chemical Toxicology., 45, 1478-1486.

Kalender, Y., Uzunhisarcikli, M., Ogutcu, A., Acikgoz, F., \& Kalender, S. (2006). Effects of diazinon on pseudocholinesterase activity and haematological indices in rats: The protective role of vitamin E. Environmental Toxicology and Pharmacology, 22(1), 46-51.

Kamath, A. B., Xu, H., Nagarkatti, P. S., \& Nagarkatti, M. (1997). Evidence for the inductionof apoptosis in thymocytes by 2,3,7,8-tetrachlorodibenzop-dioxin in vivo. Toxicology and Applied Pharmacology, 142, 367-377.

Karrow, N. A., McCay, J. A., Brown, R. D., Musgrove, D. L., Guo, T. L., Germolec, D. R., \& White Jr., K. L. (2005). Oral exposure to atrazine modulates cell mediated immunefunction and decreases host resistance to the B16F10 tumor model infemale B6C3F1 mice. Toxicology, 209, 15-28.

Keggan, A., Freer, H., Rollins, A., \& Wagner, B. (2013). Production of seven monoclonal equine immunoglobulinsisotyped by multiplex analysis. Veterinary Immunology and Immunopathology, 153(3), 187-193.

Manzoor, S., Mehboob, K., \& Naveed, A. (2016). Comparison of protective effect of green tea and vitamin $\mathrm{C}$ against cypermethrin induce nephrotoxicity in mice. Journal of Ayub Medical College Abbottabad, 28(2), 241-244.

Menezes, C., Fonseca, M. B., Leitemperger, J., Pretto, A., Moraes, B. S., Murussi, C. R. , Baldisserotto, B., \& Loro, V. L. (2015). Commercial formulation containing 2, 4-D affects biochemical parameters and morphological indices of silver catfish exposed for 90 days. Fish Physiology and Biochemistry, 41(2), 323-330.

Miller, G. G., Sweet, L. I., Adams, J. V., Omann, G. M., Passino-Reader, D. R., \& Meier P. G. (2002). In vitro toxicity and interactions of environmental contaminants (Arochlor 1254 and mercury) and immunomodulatory agents (lipopolysaccharide and cortisol) on thymocytes from lake trout (Salvelinus namaycush). Fish \& Shellfish Immunology, 13, 11-26.

Mosmann, T. (1983). Rapid colorimetric assay for cellular growth and survival: Application to proliferation and cytotoxicity assays. Journal of Immunological Methods, 65, 55-63.

Murussi, C. R., Costa, M. D., Leitemperger, J. W., Guerra, L., Rodrigues, C. C., Menezes, C. C., Severo, E. S., Flores-Lopes, F., Salbego, J., \& Loro, V. L. (2016). Exposure to different glyphosate formulations on the oxidative and histological status of Rhamdiaquelen. Fish Physiology and Biochemistry, 42(2), 445-455.

Nassef, M. (2017). Immunohematological impacts induced by clomazone in Swiss albino mice: Ameliorative role of vitamin C. The Egyptian Journal of Experimental Biology (Zoology), 13(1), 91-101.

Nimmerjahn, F., \& Ravetch, J. V. (2008). Fcy receptors as regulators of immune responses. Nature Reviews. Immunology, 8, 34-47.

Ogutcu, A., Suludere, Z., \& Kalender, Y. (2008). Dichlorvos-induced hepatotoxicity inrats and the protective effects of vitamins $C$ and $E$. Environmental Toxicology and Pharmacology, 26, 355-361.

Prater, M. R., Gogal Jr., R. M., Blaylock, B. L., Longstreth, J., \& Holladay, S. D. (2002). Single-dose topical exposure to the pyrethroid insecticide, permethrin in C57BL/6N mice: Effects on thymus and spleen. Food and Chemical Toxicology, 40(12), 1863-1873.

Reddy, P. S., \& Bhagyalakshmi, A. (1994). Changes in oxidative metabolism in selected tissues of the crab (Scylla serrata) in response to cadmium toxicity. Ecotoxicology and Environmental Safety, 29(3), 255-264.
Richard, J. L., Peden, W. M., \& Williams, P. P. (1994). Gliotoxin inhibits transformation and is cytotoxic to turkey peripheral blood lymphocytes. Mycopathologia, 126(2), 109-114.

Sakazaki, H., Ueno, H., Uematani, K., Utsumi, H., \& Nakamuro, K. (2001). Immunotoxicological evaluation of environmental chemicals utilizing mouse lymphocytes mitogenesis test. Journal of Health Science, 47, 258-271.

Sakr, S.A., Mahran, H.A., Abo-Elyazid, S.M., 2005. Effect of DDB on mancozeb fungicide induced ultrastructural and biochemical changes in the liver of albino mice. Proceeding of the 9th conference on Environ. Sci. Tech. Rhodes Island, Greece, 809-815.

Salbego, J., Pretto, A., Gioda, C. R., de Menezes, C. C., Lazzari, R., Neto, J. R., Baldisserotto, B., \& Loro, V. L. (2010). Herbicide formulation withglyphosate affects growth, acetylcholinesterase activity, and metabolicand hematological parameters in piava (Leporinusobtusidens). Archives of Environmental Contamination and Toxicology, 58, 740-745.

Salehi, M., \& Jafary, M. (2010). Comparison effect of Diazinon and Parakson on Oxidative stress biomarkers of rat serum. Zahedan University Medical Science, $14,25-36$.

Sharma, Y., Bashir, S., Rshad, M., Gupta, S. D., \& Dogra, T. D. (2005). Effects of acute dimethoate administration on antioxidant status of liver and brain of experimental rats. Toxicology, 206(1), 49-57.

Shifrin, V. I., \& Anderson, P. (1999). Trichothecene mycotoxins trigger a ribotoxic stress response that activates c-jun $\mathrm{N}$-terminal kinase and p38 mitogenactivated protein kinase and induces apoptosis. The Journal of Biological Chemistry, 274, 13985-13992.

Shokrzadeh, M., Shobi, S., Attar, H., Shayegan, S., Payam, S. S., \& Ghorbani, F. (2012). Effect of vitamins A, E and C on liver enzyme activity in rats exposed to organophosphate pesticide diazinon. Pakistan Journal of Biological Sciences, 15(19), 936-941.

Tukmechi, A., Rezaee, J., Nejati, V., \& Sheikhzadeh, N. (2014). Effect of acute and chronic toxicity of paraquat on immune system and growth performance in rainbow trout, Oncorhynchusmykiss. Aquaculture Research, 45(11), 1737-1743.

Uzun, F. G., Kalender, S., Durak, D., Demir, F., \& Kalender, Y. (2009). Malathioninduced testicular toxicity in male rats and the protective effect of vitamins $C$ and E. Food and Chemical Toxicology, 47, 1903-1908.

Uzunhisarcikli, M., Kalender, Y., Dirican, K., Kalender, S., Ogutcu, A., \& Buyukkomurcu, F. (2007). Acute, subacute and subchronic administration of methyl parathion-induced testicular damage in male rats and protective role of vitamins C and E. Pesticide Biochemistry and Physiology, 87(2), 115-122.

Van der Oost, R., Beyer, J., \& Vermeulen, N. P. (2003). Fish bioaccumulation and biomarkers in environmental risk assessment: A review. Environmental Toxicology and Pharmacology, 13(2), 57-149.

Vandebriel, R. J., Spiekstra, S. W., Hudspith, B. N., Meredith, C., \& Van Loveren, H. (1999). Invitro exposure effects of cyclosporin A and bis(tri-n-butyltin)oxide onlymphocyte proliferation, cytokine (receptor) mRNA expression, and cellsurface marker expression in rat thymocytes and splenocytes. Toxicology, $135,49-66$.

Verma, R. S., Mehta, A., \& Srivastava, N. (2007). In vivo chlorpyrifos induced oxidative stres: Attenuation by antioxidant vitamins. Pesticide Biochemistry and Physiology, 88, 191-196.

Von König, C. H., Finger, H., \& H'Ormaycht, D. (1979). Immunoglobulins and other plasma proteins in late pregnancy (author's transl). Immunität und Infektion, 7(3), 89-92.

Wichmann, G., Herbarth, O., \& Lehmann, I. (2002). The mycotoxins citrinin, gliotoxin, and patulin affect interferon-gamma rather than interleukin-4 production in human blood cells. Environmental Toxicology, 17(3), 211-218.

Yousef, M. I., Abbassi, M. S., \& Yacout, M. H. (1999). Assessment of cypermethrin and dimethoate toxicity in Barky sheep. Biochemical and histological changes and tissue residues. Egyptian Journal of Animal Production, 36, 25-41.

Zhang, X., Wang, M., Gao, S., Ren, R., Zheng, J., \& Zhang, Y. (2011). Atrazineinduced apoptosis of splenocytes in BALB/C mice. BMC Medicine, 9(1), 117. 